\title{
CRIANÇAS E INFÂNCIA: DESDE O COTIDIANO A EDUCAÇÃO INFANTIL DO CAMPO NO TERRITÓRIO TRANSXINGU
}

\author{
Vilma Aparecida Pinho* \\ Léia Gonçalves Freitas **
}

\begin{abstract}
Resumo: Este artigo objetiva refletir sobre a educação de criança em idade pré-escola que desenvolvem a sua formação em escolas do campo na trama cotidiana da partilha de experiências com crianças maiores e com possibilidades de aprendizagens diferentes. A metodologia utilizada foi a pesquisa de campo com abordagem qualitativa. Em relação aos resultados, os dados analisados apontaram que o processo de ensino e aprendizagem das crianças pequenas atendidas em escolas do campo, considera em seu desenvolvimento a formação socioeducativa na trama cotidiana de experiências, considerando nesse percurso os deslocamentos nos espaços, as formas de organização dos ambientes e das atividades propostas, o reconhecimento de seus direitos e a realização de práticas portadoras de movimentos amplos, constituidoras da ampliação biopsicossocial.
\end{abstract}

Palavras-chave: Infância. Criança. Educação infantil do campo. Classe multisseriada. Transxingu

\section{INFANCIA Y NIÑEZ: DESDE LA COTIDIANIDAD LA EDUCACIÓN INFANTIL DEL CAMPO EN EL TERRITORIO DEL TRANSXINGU}

Resumen: Este artículo objetiva reflexionar sobre la educación de niño en edad preescolar que desarrollan su formación en escuelas en el campo en la trama cotidiana del compartir experiencias com niños mayores y con posibilidades de aprendizajes diferentes. La metodología utilizada fue la investigación de campo con enfoque cualitativo. Encuanto a los resultados, los datos analizados apuntaron que el proceso de enseñanza y aprendizaje de los niños pequeños atendidos en escuelas en el campo, consideran en su desarrollo la formación socioeducativa en la trama cotidiana de experiencias, considerando en ese recorrido los desplazamientos en los espacios, las formas de organización de los ambientes y de las actividades propuestas, el reconocimiento de sus derechos y la realización de prácticas portadoras de movimientos amplios, constituyentes de la ampliación biopsicosocial.

Palabras clave: Infancia. Niño. Educación infantil en el campo. Clase multiseriada. Transxingu.

Submissão: 12-05-2019 Aceite: 08-09-2019

\section{INTRODUÇÃO}

O objetivo nessa pesquisa é refletir sobre a educação de criança em idade préescola que desenvolvem a sua formação em escolas do campo na trama cotidiana da partilha de experiências com crianças maiores e com possibilidades de aprendizagens diferentes. Neste sentido, nos interessou investigar como ocorre o processo de ensino e aprendizagem dessas crianças e como elas desenvolvem sua formação socioeducativa na trama cotidiana de experiências com crianças maiores em salas multisseriadas, pois

$1{ }^{*}$ Professora da Faculdade de Educação da UFPA e Professora do PPGEDUC - Programa de Pós-Graduação em Educação e Cultura. Coordenadora do GEABI - Grupo de Estudos Afro-brasileiros e Indígenas.

$2{ }^{* *}$ Doutora em Educação pela Universidade Federal do Pará ( UFPA, 2019); Mestra em Educação, Linguagens e Tecnologias pela Universidade Estadual de Goiás (UEG, 2014); Especialista em Desenvolvimento de Recursos Humanos (UFPA, 2002) e Graduada em Licenciatura Plena em Pedagogia pela Universidade Federal do Pará (UFPA, 2001). É professora de Prática de Ensino e Estágios Supervisionados na Universidade Federal do Pará, Campus Altamira, atuando nas áreas da História da Infância; Educação Infantil; Pedagogia em Ambiente não Escolar e Educação para as Relações Étnico-raciais. 
na realidade investigada, território Transxingu ${ }^{3}$ que abrange alguns municípios da Transamazônica como Placas e Uruará e do Rio Xingu como é a comunidade Espírito Santo no município de Porto de Moz, encontramos o fenômeno da criança em classes multisseriadas. A criança em idade pré-escolar sendo atendida com crianças maiores nos causou estranhamento e nesse sentido, buscaremos aqui uma perspectiva de reflexão que analisa essa realidade.

No tocante à abordagem metodológica da pesquisa, a utilizada foi a qualitativa, porque segundo Minayo (1994, p. 22) e colaboradores, "responde a questões muito particulares. Ela se preocupa, nas ciências sociais, com um nível de realidade que não pode ser quantificado". Ou seja, "trabalha com o universo de significados, motivos, aspirações, crenças, valores e atitudes, o que corresponde a um espaço mais profundo das relações, dos processos e dos fenômenos que não podem ser reduzidos à operacionalização de variáveis".

Os instrumentos de pesquisa foram observação participante com foco nas práticas pedagógicas das alunas/professoras do curso PARFOR/Pedagogia UFPA ${ }^{4}$, dos anos de 2015 a 2018. As aulas aconteceram nos meses de janeiro, fevereiro e julho dos respectivos anos. A escolha pela observação participante se deu porque esta legitima a compreensão de que "as experiências diárias dos sujeitos pode tentar apreender a sua visão de mundo, isto é, o significado que eles atribuem à realidade que os cerca e às suas próprias ações" (LÜDKE e ANDRÉ, 2012, p. 26). Paralelo às observações foram acontecendo o tratamento dos dados a partir dos eixos analíticos da Sociologia da Infância, Cultura lúdica de criança e Educação Infantil do campo, com ênfase no referencial discursivo da educação do campo, nomeadamente, a partir dos pressupostos do ensino em classes multisseriadas ${ }^{5}$.

Para demarcar esse campo de estudo, fizemos um recorte temático do problema

3 Segundo Alves e Gomes (2017, p. 59), “a Transamazônica e o Xingu consistem em uma área formada por dez municípios: Altamira, Anapu, Brasil Novo, Medicilândia, Pacajá, Placas, Porto de Moz, Senador José Porfírio, Uruará e Vitória do Xingu”. Em 2003, constituiu-se território por meio da Secretaria de Desenvolvimento Territorial do Ministério do Desenvolvimento Agrário do Brasil, passando a ser chamado de 'Transxingu', tendo Altamira o município mais importante da Transamazônica e Xingu.

4 O curso de Pedagogia do Plano Nacional de Formação de Professores da Educação Básica - PARFOR, foi instituída na Faculdade de Educação/UFPA, Campus Altamira pela Portaria Normativa MEC nº 9/2009. Trata-se de uma ação do Governo Federal que visa fomentar a oferta de ensino superior gratuita, para profissionais do magistério da educação básica da rede pública sem a formação específica na área em que atuam.

$5 \quad$ As Classes Multisseriadas apresentam, enquanto característica principal a heterogeneidade ao agrupar numa mesma sala de aula alunos em diferentes anos/séries, com diferentes idades e níveis de aprendizagem, na maioria das vezes sob a responsabilidade de um único professor. A sua existência vem sendo marcada historicamente pelo descaso e o anonimato, aspectos que têm contribuído para um olhar preconceituoso quanto à materialidade dessas classes do campo. Sendo apontadas por muitos como responsáveis pela má qualidade da educação ofertada nas Escolas do Campo (SANTOS, 2016). 
da infância do campo a partir do atendimento em classes multisseriadas, realidade vivida por nós na região.

\section{EDUCAÇÃO DO CAMPO NO TERRITÓRIO TRANSXINGU}

Hage (2008), coordenador do GEPERUAZ/UFPA ${ }^{6}$, indica que a educação do campo apresenta fragilidades tanto na oferta do ensino em classes multisseriadas, quanto na qualidade de seu desenvolvimento, como demonstra pesquisas analisadas em seu artigo "A multissérie em pauta: para transgredir o paradigma seriado nas escolas do campo". No artigo citado, o autor exibe os dados do IBGE-PNAD 2005 e 2006, mostrando a taxa de analfabetismo de 24,1\%; o número de matrícula responde por 58,3\%; e a escolaridade média da população de 15 anos ou mais nas escolas campo, com menos de 4 anos de estudo o indicador é de $46 \%$.

A questão da universalidade da educação do campo ainda é desafio a ser enfrentado pelas políticas públicas, tendo em vista que o acesso à escola para crianças na faixa etária de 7 a 14 anos (idade referente à idade obrigatória) e as elevadas taxas de distorção idade-série do campo (39,4\% nos anos iniciais do EF e 53,4\% nos anos finais do EF) indicam que a grande maioria destes estudantes encontra-se matriculados nos anos iniciais do Ensino Fundamental, isto significa, pelo menos duas questões, que se refere ao avanço da escolarização dos alunos, e/ou a própria oferta que pode estar restringindo esses alunos em níveis escolares tão baixos.

As condições objetivas das escolas do campo, tais como falta de transporte, alimentação e recursos didáticos, em muito contribuem para que os pais matriculem as crianças somente após os seis anos de idade nas escolas em suas comunidades rurais. Contudo, a inserção das crianças pequenas em classes multisseriadas, evidenciou outras problemáticas que agrega ainda mais fragilidades no atendimento a crianças na Educação Infantil do campo, isto se refere ao agrupamento de crianças pequenas de crianças maiores no mesmo espaço/tempo de ensino e aprendizagem, fato que se configura um atendimento multisseriado, isto fere o disposto no $\S 2^{\circ}$ do artigo da Resolução 03/2008 CNE; a questão da ludicidade ${ }^{7}$ e as formas diferenciadas de ensino

6 É um Grupo de Estudos e Pesquisas em Educação no Campo da Amazônia, do Instituto de Ciências da Educação (ICED/UFPA).

7 A cultura lúdica como expressão do jogo e brincadeiras das crianças foi observada por nós no contexto da criança no campo, mas compreendendo que a brincadeira é uma construção histórica, social e cultural dos diferentes 
no contexto escolar do campo (HAGE, 2008).

Outras dificuldades presentes no trabalho com crianças pequenas em classes multisseriadas, que devem ser consideradas na educação do campo, a saber: 1) o avanço do processo de ensino e aprendizagem proposto na grade curricular e um currículo distanciado da realidade cultural, do trabalho e da vida do campo, dificultando assim, o alcance dos objetivos esperados; 2) falta de materiais didáticos e pedagógicos para trabalhar com crianças pequenas; 3 ) formação adequada dos professores para o trabalho com multissérie; 4) inexistência de infraestrutura e condições de trabalhos adequados; 5) a sobrecarga de trabalho dos professores e instabilidade no emprego; 6) as angústias relacionadas à organização do trabalho pedagógico; 7) o fracasso escolar e a defasagem idade-série são elevados em face do pouco aproveitamento escolar e das atividades de trabalho infanto-juvenil; 8) dilemas relacionados à participação da família e da comunidade na escola; 9) e a falta de acompanhamento pedagógico das secretarias de educação. Essas dificuldades da educação do campo para o autor decorrem de uma série de fatores que somados a ineficiência de planejamento e gestão das políticas públicas concorrem para o fracasso das condições educacionais, acesso e permanência das crianças pequenas na escola.

Para Hage (2008), essas dificuldades são consideradas quando a compreensão de criança se pauta no sujeito que produz cultura e que aprende a partir das ressignificações da realidade em um processo dinâmico e dialético que observa, compreende e interferem na sociedade pela sua presença humana, política e cultural. Essa noção de criança baseia-se do campo da Sociologia da Infância, a partir dos princípios de sujeitos socioculturais, onde as ações cotidianas ocorrem no contexto da produção da cultura e dos fazeres vividos em relação às rotinas e dinâmicas das múltiplas realidades. Nessa acepção as "crianças produzem uma série de culturas locais que se interagem e contribuem para as culturas mais amplas de outras crianças e adultos, cujo contexto elas estão integradas" (CORSARO, 2011, p. 127).

Uma questão a se considerar nesse debate é a noção de criança como sujeito sociocultural produtor. Neste caso, os planejamentos escolares consideraram o desenvolvimento de atividades lúdicas, o reconhecimento dos diferentes grupos sociais, a proteção contra qualquer forma de violência e a efetivação do trabalho coletivo como prática contínua para garantir os meios pelos quais as crianças possam ser reconhecidas 
e valorizadas a partir das diversidades culturais, caso contrário, a escola do campo não cumpre papel de mediadora de conhecimentos, por vezes considerada,

[...] uma não escola, não educandário, sem qualidade, os educadores-docentes, como não educadores, não docentes; a organização curricular não seriada, multisseriada, como inexistente; os diversos povos do campo, na pré-história, na inferioridade cultural [...] (ARROYO, 2015 p. 10-11).

Superar esse pensamento exige da comunidade escolar a elaboração de estratégias e possibilidades que permita o desenvolvimento de aprendizagens significativas, pois

quanto mais se entende a diversidade de dimensões e, portanto, as especificidades do campo, mais se afirma a necessidade de uma educação e de uma escola que atenda e alimente essa dinâmica formadora, tanto da sociedade quanto dos indivíduos, definindo cada vez mais, a função social da educação e da escola em um projeto de inserção do campo no conjunto da sociedade (PACHECO; PIOVESAN, 2014 p. 51).

É preciso investimentos que possibilite ampliações e modificações para que as crianças pequenas tenham oportunidade de estudo com qualidade e consignam ampliar seus conhecimentos ao longo de suas vivências para superar o retrato da região Transxingu que por ora se apresenta com ações pontuais de oferta educacional fragilizada em classes multisseriadas caóticas. Todos esses fatores contribuem para o fracasso das escolas do campo, que por vezes, ficam esquecidas, sem investimentos e sem a promoção de um ensino de qualidade efetiva.

\section{A ESPECIFICIDADE DO CAMPO: DA CRIANÇA-INFÂNCIA À EDUCAÇÃO INFANTIL}

O despertar nas comunidades da Transxigu ocorre muito cedo, antes mesmo de o sol nascerem razão da vida do campo ser cheia de atividades domésticas, trabalhos na roça e para as crianças pequenas a ida à escola por meio de barcos ou ônibus escolares oferecido pelas prefeituras. A rotina dessas crianças é marcada por atividades que exigem disciplina e organização. Em casa executam trabalhos familiares como limpeza, cuidado com os animais domésticos, lavar roupa, buscar água no rio ou igarapé, buscar lenha no mato e ainda ajudar as mães a faz caieiras ${ }^{8}$. Essas atividades são consideradas 
femininas; aos meninos exige-se ajudar os pais no cultivo e colheita de alimentos necessários a subsistência. Além disso, as crianças atualizam os temas da escola, brincam, passeiam a pé, a cavalo ou de búfalo. Ou seja, as rotinas das crianças do campo da região transamazônica e Xingu se assemelha as constatações das pesquisas de Kishimoto (1993) e Corsaro (2011) ao tratarem de crianças ativas e sujeitos na produção cultural de seus grupos sociais.

Nesse sentido, os fazeres domésticos, na roça e na comunidade se constituem importantes processos de aprendizagem, socialização e transformação da realidade pelas crianças na interação com seus pares ${ }^{9}$, fato que se configura dimensões humanas, sociais em orais ${ }^{10}$ de sua formação, e, observamos que a educação é uma prática social cotidiana, conforme aprendemos com Brandão, (2007, p. 10), “A educação é, como outras, uma fração do modo de vida dos grupos sociais que a criam e recriam, entre tantas outras invenções de sua cultura, em sua sociedade".

Dessa forma, a educação é um processo contínuo que abrange o ser integral, pois ela existe sob tantas as formas, em diferentes contextos e situações que muitas vezes, parece invisível. A educação como prática criadora é aquela que não se reduz,

\begin{abstract}
À preparação para fins exclusivamente utilitários, como uma profissão, nem para o desenvolvimento de características parciais da personalidade, como um dom artístico, mas abrange o homem integral, em todos os aspectos do seu corpo e da sua alma, ou seja, em toda a extensão de sua vida sensível, espiritual, intelectual, moral, individual, doméstica e social, para elevá-la, regulá-la e aperfeiçoá-la. É processo contínuo, que começa nas origens do ser humano e se estende até à morte (BRANDÃO, 2007, p. 64).
\end{abstract}

No cotidiano das comunidades da Transxingu, esse tipo de educação estende-se ainda na hora das refeições, momentos ricos de convívio e diálogo; nas pescarias, onde ocorrem interações sociais e múltiplas aprendizagens; no campo de futebol, no rio, na beira das praias, nas brincadeiras ao ar livre e em todas as ações compartilhadas com a família em um processo de aprendizagem contínua. A riqueza cultural das crianças do campo, marcam uma infância de alteridade e diferença que se expressa por suas

\footnotetext{
depois joga a terra até não aparecer nenhuma lenha, porém deixa-se uma abertura na parte frontal da Caieira que funciona como suspiro, evitando assim que o fogo apague antes do tempo certo para formar as pedras de carvão.

9 A cultura de pares é um conjunto de atividades, rotinas, valores e interesses que as crianças produzem e compartilham na interação com seus pares (CORSARO 2011).

10 Como ser moral, o sujeito é aquele que se orienta, "que se agarra e se mantém no espaço moral; e a consciência, a este primeiro nível, pelo menos, não é outra coisa senão esta orientação, este agarrar-se e este manterse [aceito]" (RICOEUR, 1995b, p. 187).
} 
criações artísticas corporais que liga de maneira intrínseca aos significados e sentidos de possibilidades de invenção e representação da criança (corpo) que joga, corre, se expande na transcendência do simbólico para a representação da realidade como se expressam as brincadeiras e jogos de meninas e meninos que vivem na transxingu.

FIGURAS 1 e 2 - Meninas no campo brincando com galhos secos de árvores e meninos no cuidado com búfalos

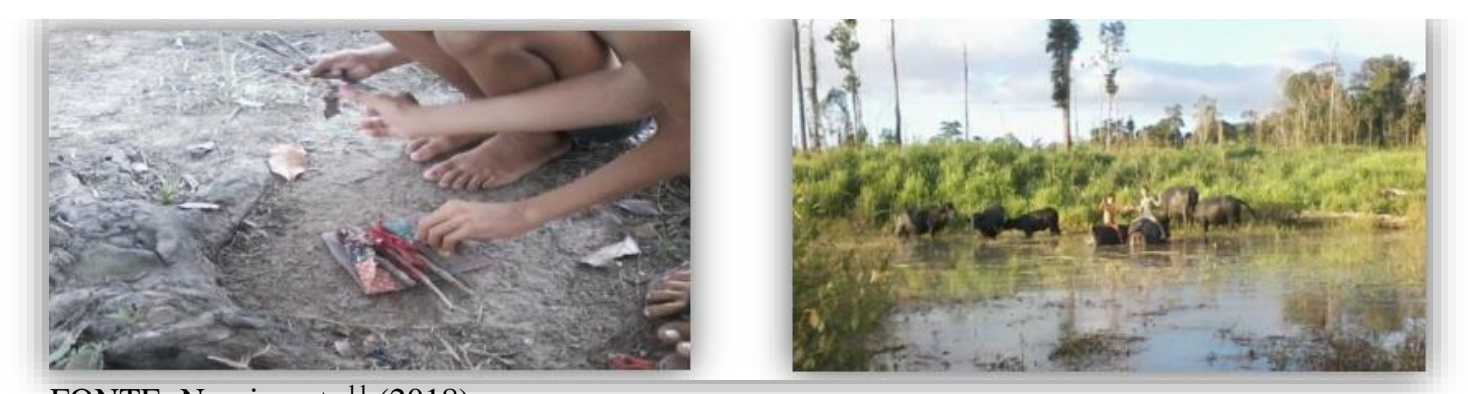

FONTE: Nascimento ${ }^{11}$ (2018)

A reprodução da realidade social da criança do campo se observa também pelas brincadeiras de infância, ao criar bonecas de galhos secos com retalhos e papelão para representar famílias, as crianças dizem: "minha filhinha dorme tranquila vizinha, quando ela acordar vai querer comer, por isso tenho que ir pra roça buscar macaxeira para fazer o mingau dela", a representação da realidade é evidenciada, pois logo, os objetos ganham vida; o cotidiano são transportados para o mundo da imaginação, dando às criações, sentido sobre seus lugares e sobre si mesmas.

As culturas das crianças do campo são ricas em experiências e artefatos socioculturais que dão sentidos e significados diferenciados a existência humana, pois elas se articulam com a natureza - partem de suas criações, brincadeiras, interação e ressignificações lúdicas. Situação que nos reporta à Guilles Brugère para quem o lúdico tem uma impregnação cultural, tendo em vista que quando a criança joga "dispõe de significações, de esquemas em estruturas que ela constrói no contexto de interações sociais que lhe dão acesso" (BRUGÈRE, 2011, p. 28).

Nesse sentido, a criança do campo no seu contexto brinca, joga, cria culturas 
lúdicas, considerando-se um conjunto de regras e significações que a constitui pelos seus processos de criações e disposições sociais e significativas do brincar.

O jogo, os brinquedos e as brincadeiras na formação da criança são importantes, pois o lúdico como vivência necessária a humanização do ser, perpassa por questões filosóficas, do direito, da sociedade e da própria organização da vida e dos pensamentos, tendo como base o corpo brincante que vive afetos, contatos, ideias e sensações do ser que irradia percepções e interage com o mundo. O brincar por si só tem cunho educativo, mas como atividade espontânea é rica por sua natureza de criação, imaginação, interação corpo, objetos e significados. Como afirma Huizinga (2000, p. 42):

Desde já encontramos aqui um aspecto muito importante: mesmo em suas formas mais simples, ao nível animal, o jogo é mais do que um fenômeno fisiológico ou um reflexo psicológico. Ultrapassa os limites da atividade puramente física ou biológica. É uma função significante, isto é, encerra um determinado sentido. No jogo existe alguma coisa "em jogo" que transcende as necessidades imediatas da vida e confere um sentido à ação. Todo jogo significa alguma coisa [...].

O ser humano quando inventa um jogo ou brincadeira, não joga por jogar, ele busca um significado no jogo, seja ele na competição de quem vence, ou em busca de treinar suas habilidades, assim o jogo sempre tem se tornado um meio de diversão, de prazer, de autoconfiança, de quem o pratica.

A representação que a criança faz de sua sociedade por meio do brincar dá vida à natureza pelas próprias percepções nas corporeidades afetivas e subjetivas de identificação com seu espaço de produção da realidade. Nesse sentido, tudo ganha vida: a lida com os animais domésticos, o manuseio com o gado, as relações de trabalho e as representações familiares.

A professora solicita aos alunos que façam registros usando os materiais que utilizam para brincar nas horas livres. Após essa ação orienta: "agora que você fez os membros de sua família, descreva para seus colegas quem são as pessoas que moram com você e como elas vivem?" O menino abaixou a cabeça por alguns segundos e em seguida exclama:

Professora eu fez a minha mãe que é bonita e muito boa comigo, ela é alta, magra, morena e gosta que eu venha pra escola, meu pai é moreno também e alto e as vezes não quer que eu venha pra escola, ele acha que eu podia tá na roça com ele, isso ia ajudar mais do que na escola, ele diz que a escola hoje mais atrapalha do que ajuda, os professores faltam 
muito e os alunos não sabe ler e nem escrever. O desenho gitito ${ }^{12}$ é meu irmão que ainda é bebê e chora muito.

Apesar de diferentes, ambos os casos trazem a representação da escola como espaço não exclusivo para promover a educação, pois especificamente nas comunidades rurais o conhecimento prático, resultado da (con)vivência, da experiência, já não encontram na educação formal respaldo fundamental, isto porque entende-se que ao longo da vida, ocorre aprendizagem. Logo, o aprendizado passa a ser entendido como um processo não institucionalizado, que ocorre nos mais variados espaços e a qualquer tempo. McLuhan(1986, apud. CARBONELL, 2016, p. 3) afirma que:

A maior parte do ensino acontece fora da escola. A quantidade de informação comunicada pelos jornais, revistas, filmes, canais de televisão e rádios excedem em grande medida a quantidade de informação comunicada pela instrução e textos na escola. Este desafio destruiu o monopólio do livro como ajuda para o ensino e derrubou os próprios muros das escolas de um modo tão repentino, que estamos confusos, desconcertados.

Todavia, lembramos que essa compreensão de educação não se aplica às comunidades da Transxingu, onde o acesso à informação via jornais, revistas, filmes, canais de televisão e rádios é difícil em função das condições econômicas, políticas e de mobilidade das escolas do campo. A educação escolar e a informal ${ }^{13}$, via de regra, são as mais comuns nos contextos rurais. Na prática, segundo Brandão (2007), a mesma educação que educa, pode também (des)educar.

Nas comunidades do campo do território Transxingu, as educações representam um domínio próprio de trocas de símbolos, intenções, crenças, padrões de cultura e de poder. E esta ideia explica as formas variadas de situações que algumas vezes pareciam invisíveis das tantas formas de práticas e ações vivenciadas pelas crianças tanto na rotina diária de sua família, quanto da escola.

Essas ações envolviam aquisição de sentimentos e disposições de condutas dos membros e de suas regras sociais, bem como processos formalizados de plasticidade, criatividade e transferências de sabedoria acumulada ao longo da vida, ocorrendo o que Brandão (2007, p. 18), chama de fluência dos saberes. Neste sentido, argumenta o autor: "as pessoas convivem umas com as outras e o saber flui, pelos atos de quem sabe-e-faz, para quem não-sabe-e-aprende".

12 Termo muito usado pelos camponeses do Xingu, que significa pequeno.

13 Trata-se da educação passada de geração a geração, em casa, na rua, na igreja, na comunidade (BRANDÃO, 2007). 
Essas formas de aprendizagem requer envolvimento do corpo, da mente, da afetividade da criatividade, para que haja trocas entre as crianças, que tornar-se-ão pessoas melhores, politicamente atuante e socialmente ativas. Pessoas que interagem com o meio significativamente, capaz de construir personalidades polidas conduzidas por uma prática transformadora e com sabedoria amorosa. A sabedoria do amor tem na intencionalidade de fluir no outro à percepção da alteridade ${ }^{14}$. Assim, a relação com o outro considera, justamente, a bondade, o respeito e o amor como sentimento. O encontro com o outro - que sofre - e, por consequência, a manifestação do simples amor como disposição do amar. Neste interim, o que está em jogo é a sensibilidade humana, alicerçada na sabedoria do amor. Trata-se de perceber o outro, como alguém que está disposto a ensinar o que é o amor, seja como louvor ${ }^{15}$ ou como obrigação ${ }^{16}$.

Esse amor estava manifestado nas produções, nas brincadeiras e nas relações. Por meio da ludicidade, as crianças demonstravam sabedoria amorosa seja entre eles, ou com os animais, ao mesmo tempo em que reproduzia as ações cotidianas por meio de suas falas, gestos e sons. Os acontecimentos da rotina comunitária e da família tinham significados pela consciência produtiva - parte de sua cultura.

A sabedoria amorosa é socializada nos vastos momentos em que elas (re)produzem as atividades dos pais, como demonstrado na figura 2, onde meninos ajudam os pais a cuidarem dos búfalos. Quando as crianças vão buscar o gado no campo para um lugar seguro, à tardinha, o pastoreio não é considerado um trabalho penoso, mas uma brincadeira, uma diversão, logo, os caroços de inajá e de tucumã foram os animais da fazenda, eles separavam os garrotes das vacas justamente para fazerem a retiradas do leite e, diziam que as vacas ficavam em um curral separado dos garrotes porque precisam alimentar "os filhotes, dar leite para o queijo e para os adultos".

Apesar da criança ainda não entender que essas ações, mesmo envolvendo ludicidade, expressam a realização de um trabalho doméstico, podem elas ser consideradas lúdicas, tal como as brincadeiras nas águas do Rio Xingu de pira cola ${ }^{17}$, registrado na figura 3 .

14 Alteridade, como "uma variedade de experiências de passividade, entremeadas de maneiras múltiplas ao agir humano" (RICOEUR, 1991a, p. 371).

15 O discurso aqui empreendido é a exaltação da humanidade para glorificação, expresso na passagem bíblica de Mateus 5:3: "Bem aventurados os pobres de espírito, porque deles é o reino dos céus" (RICOEUR, 2012, p. 7). Essa peculiaridade do discurso do amor se aproxima do discurso de benção; poesia bíblica que eleva o amor à categoria positiva e superior da pessoa.

16 O discurso, neste momento, é a imposição do amor. Ricoeur (2012) argumenta que é escandaloso impor ao outro o amor, pois este é um sentimento: alteridade e respeito.

17 Brincadeira infantil muito comum entre as crianças do campo. 
FIGURA 3 - Crianças brincando de Pira Cola, Comunidade São Tomé, na Vila Maripi
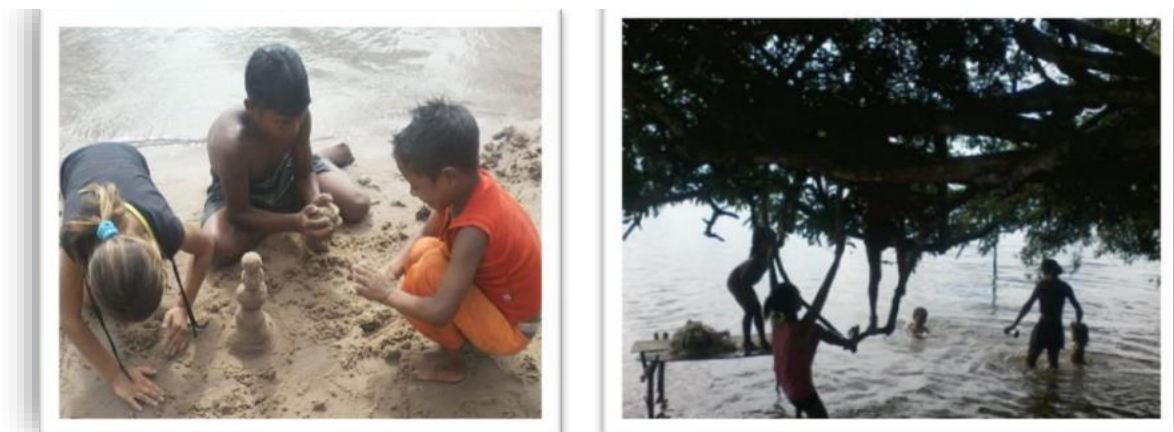

FONTE: Marinilce Nascimento, na Vila Maripi ${ }^{18}$, quando realizávamos uma pesquisa de campo da disciplina de Antropologia do Meio Rural.

O que defendemos é que no território Transxingu, as crianças vivem um cotidiano sociocultural emaranhado por costumes e valores regionais que misturam vida real e imaginária, que por vezes, confundem ou se (in)visibilizam em meio às práticas sociais e, nesse processo, elas recriam sentidos e significados nos seus fazeres de infância que as ajudam a se construírem como crianças. O certo é que ao brincarem em baixo das árvores, elas sobem e descem pelos galhos, pulam no rio sem medo; a destreza das peraltices é sempre acompanhada por risos e desenvoltura.

Quando as crianças vão banhar elas imitam as ações de sua mãe. Brincam de lavar roupas, de lavar louças e preparar os alimentos, constroem castelos e bolos de areia. Na comunidade Maripias culturas infantis advém da formação familiar e comunitária recebida ao longo dos anos, manifestada, por vezes, nas trocas abordadas por Kishimoto (1993), quando destaca que "o predomínio de brincadeiras junto à natureza, nos rios, em bandos, é uma característica do modo de brincar indígena.

As crianças mesmas criam situações de desenvolvimentos humanos nas suas dimensões físicas, motoras, sociais e culturais. Na escola em particular, as brincadeiras se apresentam como possibilidades diferenciadas de processos de ensino e aprendizagem, a partir de modos coletivos de trocas de experiências e vivências refletidas nas praticas Pedagógicas da formação das crianças.

\section{EDUCAÇÃO DO CAMPO NA ESCOLA DAS COMUNIDADES}

No contexto de classes multisseriadas, as crianças pequenas aprendem juntas com as maiores, em uma situação colaborativa e dinâmica. Porém é cabível 
consideramos que segundo dados do Censo Escolar 2009, porcentagem de crianças de 0 a 5 anos do campo, matriculadas em creches e pré-escolas, é somente 28\%. Em 2008, a taxa de frequência das crianças de 0 a 3 anos de idade era de 6,84 e, de 4 e 5 anos, era de 42,66, bem inferiores à da população urbana (respectivamente 20,53 e 62,57).

Esse quantitativo em relação a matricula e à frequência de crianças pequenas nas escolas do campo é preocupante, haja vista que todas as crianças brasileiras têm direito de convivência, permanência e acesso aos espaços, materiais e brincadeiras que possibilitem a vivência das infâncias em diferentes contextos, para que possam encantar e descobrir conhecimentos e saberes produzidos pela humanidade em grupos diversos, cujas interações cotidianas, visou a integração dos seus membros, adultos e crianças (SILVA; PASUCH, 2010). Mas, esse direito tem sido marcado por desigualdades de classe, raciais e regionais que vem reconfigurando os modos de participação da criança nas escolas do campo.

Então, como garantir às crianças do campo direito às vagas, acesso, permanência e condições de vivenciar as infâncias de forma plurais e imersas em grupos socioculturais, construindo com adultos e outras crianças, sua autoestima e suas identidades pessoais e coletivas? Para nós o primeiro passo é discutir e implantar a partir das experiências já acumuladas de educação infantil urbana e educação do campo, a educação infantil do campo que conceba as crianças, como sujeitos de direitos, valorizando e incorporando às práticas pedagógicas, às experiências delas e de suas famílias; os tempos e os espaços, os modos de convivências e as produções do campo, permitindo"que as crianças conheçam as formas como suas comunidades nomeiam o mundo, festejam, cantam, dançam, contam histórias, produzem e preparam seus alimentos" (SILVA; PASUCH, 2010, p. 3).

O desafio é construir uma educação do campo com o corpo e alma do campo com a organização curricular, de tempo, espaço, atividades e planejamentos que considera as rotinas e os ciclos das comunidades e suas formas e modos de vida, atrelado aos conhecimentos científicos da área já produzidos, tal como prever as Diretrizes Curriculares da Educação Infantil - DCNEI, no artigo $8^{\circ}$ ao abordar as questões relacionadas à elaboração da proposta pedagógica das instituições de ensino urbano e do campo, em relação à garantia do acesso a processos de apropriação, renovação e articulação de conhecimentos e aprendizagens de diferentes linguagens da criança, assim como o direito à proteção, à saúde, à liberdade, à confiança, ao respeito, à dignidade, à brincadeira, à convivência e à interação com outras crianças. 
Especificamente, no tocante à educação infantil do campo, propõem esse instrumento normativo que as propostas pedagógicas da Educação Infantil das crianças filhas de agricultores familiares, extrativistas, pescadores artesanais, ribeirinhos, assentados e acampados da reforma agrária, quilombolas, caiçaras, povos da floresta, devem:

I - reconhecer os modos próprios de vida no campo como fundamentais para a constituição da identidade das crianças moradoras em territórios rurais;

II - ter vinculação inerente à realidade dessas populações, suas culturas, tradições e identidades, assim como a práticas ambientalmente sustentáveis;

III - flexibilizar, se necessário, calendário, rotinas e atividades respeitando as diferenças quanto à atividade econômica dessas populações;

IV - valorizar e evidenciar os saberes e o papel dessas populações na produção de conhecimentos sobre o mundo e sobre o ambiente natural;

$\mathrm{V}$ - prever a oferta de brinquedos e equipamentos que respeitem as características ambientais e socioculturais da comunidade (BRASIL, 2009).

É importante considerar, que esses incisos são resultados de lutas coletivas de movimentos da sociedade civil organização em prol de uma educação infantil do campo com qualidade e que eles apontam avanços na consolidação de práticas pedagógicas críticas e políticas da educação de crianças pequenas e na construção de identidade própria de ensino e aprendizagem voltada para meninos e meninas do campo em salas multisseriadas ou não, isto se considerarmos o disposto na Lei de Diretrizes e Base da Educação Nacional - LDB, Lei no 9.394/96, que assegura que "a Educação infantil, tem como finalidade o desenvolvimento integral da criança até seis anos de idade, em seus aspectos físico, psicológico, intelectual e social, complementando a ação da família e da comunidade" (BRASIL, 1996).

Reconhecidas legalmente, como sujeitos de direitos, as crianças têm necessidades de se desenvolverem de forma integral sem restrição até os seis anos de idade. Todavia, mesmo sendo a educação infantil é um direito básico firmado mediante vários documentos legais: (Constituição Federal, LDB, DCNEI e outros) que dão base jurídica a tais direitos, destacamos que a consolidação destes dispositivos legais só é alcançada quando de fato fazem-se presentes nas propostas pedagógicas das escolas de educação infantil do campo e, consequentemente nas salas de aula e nas práticas docentes, por meio das atividades dos educadores. Nesta perspectiva, Barbosa (2010, p. 3) ressalta que em uma instituição urbana ou do campo, 
intencionalidade somente é conquistada mediante uma proposição curricular explícita. Além dessa explicitação, é fundamental uma formação profissional sólida dos docentes, um olhar sensível e atento do professor e a disposição em oferecer às crianças oportunidades de conhecer aquilo de mais instigante e importante que o mundo apresenta à nossa sensibilidade e racionalidade, em situações que, ao mesmo tempo, as desafiem e as aconcheguem.

O processo educativo, para esse autor, ao ser mediado pela ação intencional dos professores, a educação das crianças pequenas é pensada como algo cultural, assim como as reflexões sobre as aprendizagens, as compreensões relacionada também à diversidade social e à identidade infantil, visto ser a criança,

Sujeito histórico e de direitos que, nas interações, relações e práticas cotidianas vivencia, constrói sua identidade pessoal e coletiva, brinca, imagina, fantasia, deseja, aprende, observa, experimenta, narra, questiona e constrói sentidos sobre a natureza e a sociedade, produzindo cultura (BRASIL, 2009, p. 12).

Assim, é importante ressaltar que a criança é um ser em construção e que necessita experimentar, vivenciar, questionar o mundo a sua volta dentre outros aspectos para construir sua identidade e desenvolver seu papel na sociedade, que é o de ser criança em suas mais distintas formas. Para tanto, as vivências e os conhecimentos de mundo precisam ser integrados às propostas pedagógicas das escolas, mas também às práticas docentes, possibilitando, momentos de aprendizagens para estes sujeitos. Momentos que garantam os meios pelos quais as crianças possam ser reconhecidas e valorizadas na diversidade de cultural, na interação com os outros, tornando o ambiente um espaço social de aprendizagem com os mais diferentes grupos sociais. Destarte, as instituições de educação infantil do campo consideraram em suas atividades a ludicidade, experiências sensoriais, afetivas, estéticas, éticas, políticas e ambientais vividas pelas crianças, bem como, o reconhecimento dos diferentes grupos sociais. Em campo de pesquisa, verificamos que as atividades educativas nas comunidades respeitavam essas prerrogativas, especialmente, ao adotar medidas de interações lúdicas entre as crianças, no ato das brincadeiras e das confecções dos jogos didáticos.

Durante as brincadeiras, as crianças eram incentivas pelas professoras a aprender de forma lúdica, proporcionando-lhes por meio de ações didáticas prazerosas, dinâmicas e eficientes o desenvolvimento na resolução de problemas, requerendo para tanto, habilidade de leitura, escrita e domínio numérico, exigidos paulatinamente durante as brincadeiras, donde o interesse das crianças, o empenho em aprender e o 
envolvimentos até mesmo no horário do recreio era constante, como podemos verificar na miscelânea de fotos na figura 4 , onde os alunos participam ativamente das atividades dirigidas pela professora em sala de aula em relação aos conhecimentos matemáticos e linguísticos.

FIGURA 4 - Alunos da Educação Infantil do campo em atividade lúdicas em salas multisseriadas

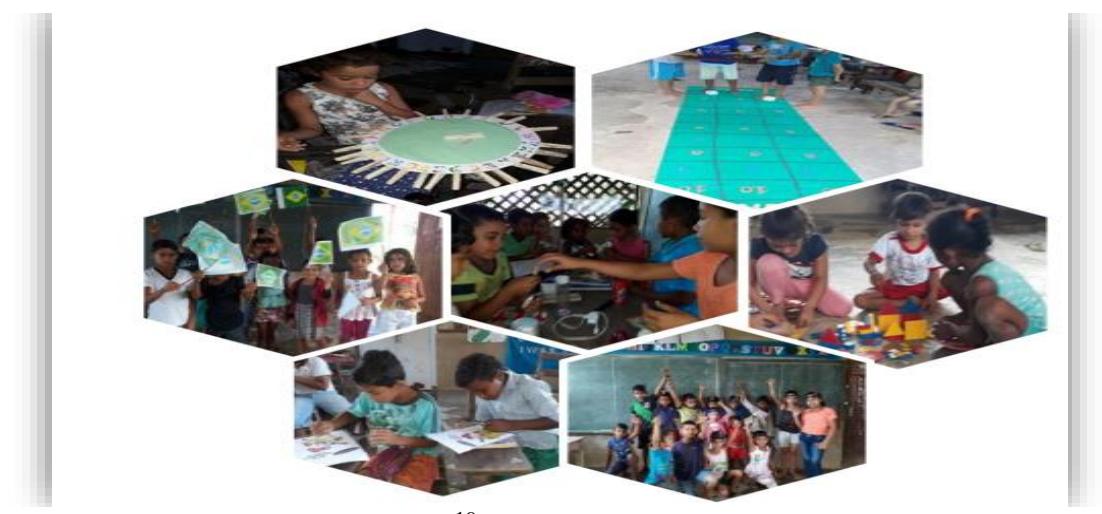

FONTE: Arquivo pessoal Diana Leite (2018) ${ }^{19}$.

Cada atividade foi cuidadosamente planejada pelas professoras das comunidades Espirito Santos, Maripi, e na EMEIF Flor da Serra na Transxingu. O círculo alfabético, por exemplo, foi confeccionado pelas crianças com o objetivo de elas associarem o alfabeto minúsculo cursivo com o alfabeto em bastão, aprender os códigos silábicos e alfabéticos e ainda associar as cores.

A encenação de um teatro, onde as crianças representavam a comercialização de produtos e serviços característicos de suas comunidades, ajudaram-nos a realizar pequenas tarefas como compra e venda. O objetivo era ajudá-las no processo de valorização de moedas, aprender a reconhecer números e quantidades, calcular, passar e receber troco e, trabalhar com valores reais de compra e venda de mercadorias do seu

19 Aluna do curso de Licenciatura em Pedagogia - PARFOR/ UFPA, moradora da comunidade Espirito Santo, colaboradora desta pesquisa. 
ambiente econômico e social. As professoras observadas realizaram ainda a dramatização de uma feira livre, onde os alunos ficaram empolgados e envolvidos no evento. Além disse identificamos que: 1) as aulas sobre noções geométricas com as crianças da educação infantil eram sempre carregadas de risos e gritaria, pois as elas brincavam e aprendiam construindo castelos com montagens de uma variedade de tamanho e peças coloridas, nem sempre industrializadas; 2) nas aulas de artes, meninos e meninas realizam leituras de lendas brasileiras, com material colado em caixa de papelão e recortes de jornais e revistas velhas. Ainda havia colagem de pedras, sementes e folhagem, tudo era pensado de acordo com a realidade do campo. Enfim, o objetivo era trabalhar a conscientização ecológica e a responsabilidade social das crianças com o desenvolvimento sustentável da Transamazônica e Xingu.

O destaque dessas atividades é a formação sociocultural e política dessas crianças, além disso, de modo geral, o resultado dessas ações didáticas impactou sobremaneira o desenvolvimento motor, afetivo, cognitivo, linguístico, ético e estético das crianças, pois segundo uma das professoras observadas, elas proporcionaram:

Aprendizado significante para as crianças e para mim, pois foi pesquisando em uma etapa do PARFOR, para apresentação de oficinas, que tive acesso a esses recursos didáticos, trouxe-os para escola e tem me ajudado bastante nesse processo de ensino; e para as crianças que tem dificuldade de aprendizado que se relacionam com outras faixas etárias, esses recursos me ajudou sobremaneira, pois os que já sabiam ensinavam aos outros e assim todos aprendiam em conjunto uns ajudando outros, compartilhando conhecimentos. Isso é lindo: ver como as crianças gostam de compartilhar com os colegas seus conhecimentos (PROFESSORA/ALUNA DO PARFOR/UFPA, 2018).

Inferimos a partir disso, que o uso de recurso didáticos diferenciado em sala de aula é trabalhoso e requer do professor um olhar atento, ao mesmo tempo, demanda um olhar crítico para suas ações educativas, principalmente quando se trabalha com Educação Infantil do campo em sala multisseriada, isto ocorre, porque para Lopes (2006), essa etapa de ensino tem suas especificidades - cuidar e educar - portanto, o educador tem papel não apenas de mediador da ação educativa, mas, sobretudo, de condutor das interações socioculturais.

No caso da promoção da interação entre crianças, em sala multisseriada, o atendimento das crianças pequenas nas comunidades estudadas, se por um lado, reafirma o direito à educação do campo na Resolução 02/2008 CNE, no artigo $3^{\text {o: }}$ “a educação infantil e os anos iniciais do ensino fundamental serão sempre oferecidos 
nas próprias comunidades rurais, evitando-se os processos de nucleação de escolas e de deslocamento das crianças" (BRASIL, 2008), por outro lado ao regular o agrupamento de crianças na Educação Infantil do campo, fere o disposto no $\S 2^{\circ}$ do artigo $3^{\circ}$ quando registramos a existência de um marco divisor da especificidade: "Em nenhuma hipótese serão agrupadas em uma mesma turma crianças de educação infantil com crianças do ensino fundamental" (BRASIL, 2008).

Apesar disso, o que importa é pontuar que as Orientações Curriculares Nacionais para a Educação Infantil do Campo, apontam para que haja a preocupação da organização de tempos, espaços e atividades que condigam com a promoção das interações variadas considerando o tempo da atividade proposta, as singularidades do grupo e as relações estabelecidas. Igualmente, os grupos de crianças pequenas podem participar dos grupos de crianças maiores, respeitando as singularidades e as demandas diversificadas entre elas, sem segregar, isolar ou restringir oportunidades de aprendizagem e ricas interações.

As interações socioculturais em diferentes grupos e contextos é prevista no artigo $7^{\circ}$ da DCNEI quando ela aborda a função sociopolítica e pedagógica das instituições de Educação Infantil, onde inclui: garantia das condições para a vivência da infância; o compartilhamento com a família da responsabilidade de educação da criança; a ampliação do conhecimentos da criança em contexto de interação com outras crianças; a promoção da igualdade de oportunidades entre crianças; a construção de novas formas de sociabilidade e subjetividades comprometidas com o rompimento de relações de dominação (SILVA; PASUCH, 2010).

\section{CONSIDERAÇÕES FINAIS}

O trabalho docente na Educação do Campo em classes multisseriadas é imenso, intenso e, por vezes, apresentam as dificuldades, a saber: o trabalho com crianças em diferentes idades e níveis de aprendizagens em uma mesma sala de aula é por deveras dinâmico e exige formação específica do professor; a falta de materiais didáticos e pedagógicos como livros e brinquedos; o não acompanhamento pedagógico da gestão municipal de educação; as várias funções exercidas pelo professor; a falta do transporte escolar público, gratuito e com qualidade; a constante falta da merenda escolar e a frágil estrutura física da escola com seus móveis velhos e sem condições de segurança para as crianças. 
Essa triste realidade das más condições de funcionamento da escola do campo, em especial, do atendimento da educação infantil do campo advêm da ineficácia da aplicabilidade dos instrumentos legais e o não cumprimento das determinações dos direito infantis como prerrogativas fundamentais do acesso às vagas e permanecia de crianças pequenas nas escolas de suas comunidades, tal como previstos na DCNEI, Diretrizes Operacionais para a Educação Básica nas Escolas do Campo (Resolução CNE/CEB n1, 03 de abril de 2002), Parecer CNE/CEB 36/2001, Parecer CNE/CEB 03/2008 e a Resolução CNE/CEB 02/2008. Neste sentido, inferimos que a realidade das comunidades da Transxingu, não se difere das demais regiões do Brasil, onde as escolas do campo são resultantes das mobilizações e reivindicações sociais por uma educação de qualidade. Essas mobilizações refletiram para algumas, investimentos, para outras quase nada, gerando quase sempre, por parte do professor, investimentos próprios, tendo que tirar do seu salário recursos para compra de materiais de trabalho.

É evidente que os problemas enfrentados por esses professores nas escolas do campo são episódios rotineiros. Os governos se (des)responsabilizam pela educação "assistido" ora a distância, ora tendo acesso às informações da crucial tarefa de educar em salas multisseriadas por intermédio de estatísticas nem sempre confiáveis. Entretanto, com todas essas mazelas existentes causadas também pelo descaso e pelo esquecimento do poder público, na Transxingu, há professoras que buscam estratégias e metodologias lúdicas e diferenciadas para trabalhar com as crianças em classes multisseriadas, onde muitas delas devido às péssimas condições estruturais e pedagógicas não obtêm aprendizagem e desenvolvimento significativo. Essas professoras lutam nessa região por mudanças significativas que melhore o trato dos problemas das comunidades locais, ampliando os conhecimentos e saberes sobre a real situação das condições de vida, da convivência, do trabalho e do lazer dos espaços e lugares de moradia. Por fim, essas professoras são atuantes em buscar em suas comunidades estratégias e metodologias que primam pelo desenvolvimento integral da criança pequena nas suas relações com as crianças maiores.

Destarte, o retrato da educação infantil do campo na Transxingu reflete uma educação em classes multisseriadas, com aparatos voltados para a partilha de experiências entre crianças pequenas e maiores e com possibilidades de aprendizagens diferentes. Neste sentido, o processo de ensino e aprendizagem dessas crianças, considera em seu desenvolvimento a formação socioeducativa infantil na trama cotidiana de experiências, considerando nesse percurso os deslocamentos nos espaços, 
as formas de organização dos ambientes e das atividades propostas, o reconhecimento de seus direitos e a realização de práticas portadoras de movimentos amplos, constituidoras da ampliação biopsicossocial.

\section{BIBLIOGRAFIA}

ALVES, Juliete Miranda; GOMES, Ramonildes Alves. O papel da Prelazia do Xingu na construção dos movimentos sociais e na formação de liderança no território da Transamazônica - PA. In: PADINHA, Marcel Ribeiro (Org.). Ergueam: Cametá, Amazônia, Brasil. Cametá: UFPA, 2017. p. 59-74.

ARROYO, Miguel G. Prefácio: Introdução. In: ANTUNES-ROCHA, Maria Isabel; HAGE, Salomão Antônio Mufarrej. Escola de Direito: reinventando a escola multisseriada. Belo Horizonte-MG: Autêntica, 2015.

BARBOSA, Maria Carmem Silveira. Os resultados da avaliação de propostas curriculares para a educação infantil dos municípios brasileiros. In. ANAIS DO I SEMINÁRIO NACIONAL: CURRÍCULO EM MOVIMENTO - Perspectivas Atuais Belo Horizonte, novembro de 2010.

BRANDÃO, Carlos. Rodrigues. O que é educação? São Paulo: Brasiliense, 2007.

BRUGÈRE, Gilles. A criança e a cultura lúdica. In Kishimoto, T, M. O brincar e suas teorias. São Paulo: Cengage Learning, 2011.

BRASIL. CONGRESSO NACIONAL. Lei $\mathrm{n}^{\circ}$ 9.394, de 20 de dezembro de 1996. Estabelece as diretrizes e bases da educação nacional. Diário Oficial da União de 23.12.1996. Disponível em: http://www.planalto.gov.br/ccivil_03/leis/L9394.htm.

BRASIL. MINISTÉRIO DA EDUCAÇÃO. CONSELHO NACIONAL DE EDUCAÇÃO. CÂMARA DE EDUCAÇÃO BÁSICA. Resolução no. 1 de 03 de Abril de 2002: Institui Diretrizes Operacionais para a Educação Básica nas Escolas do Campo. Relator: Francisco Aparecido Cordão. Diário Oficial da União, 9 de abril de 2002, Seção 1, p. 32.

BRASIL. MINISTÉRIO DA EDUCAÇÃO. CONSELHO NACIONAL DE EDUCAÇÃO. CÂMARA DE EDUCAÇÃO BÁSICA. Resolução nº. 2, de 28 de abril de 2008: Estabelece diretrizes complementares, normas e princípios para o desenvolvimento de políticas públicas de atendimento da Educação Básica do Campo. Diário Oficial da União de 29/4/2008, Seção 1, pp. 25-26.

BRASIL. Diretrizes Curriculares Nacionais para a Educação Infantil. Secretária de Educação Básica - Brasília: MEC, SEB, 2009.

CARBONELL, Jaume. Pedagogias do século XXI: bases para a inovação educativa. Tradução Juliana dos Santos Padilha. Porto Alegre: Penso, 2016. CONSTITUIÇÃO Federal. Disponível em: http://www.planalto.gov.br/ccivil_03/constituicao/constituicao compilado.htm. Acesso em: 12 set. 2016.

CORSARO, William A. Sociologia da infância / William A. Corsaro; tradução: Lia Gabriele Regius Reis; revisão técnica: Maria Letícia B. P. Nascimento. - Porto Alegre: Artmed, 2011.

DANTAS, Heloisa. Brincar e Trabalhar. In Kishimoto, T, M. O brincar e suas teorias. São Paulo: Cengage Learning, 2011. 
HAGE, Salomão. A multissérie em pauta: para transgredir o paradigma seriado nas escolas no campo. Belém, 2008. Disponível em: https://faced.ufba.br/sites/faced.ufba. br/files/multisserie_pauta_salomao_hage.pdf.

HUIZINGA, J. Homo ludens. São Paulo: Perspectiva, 2000.

KISHIMOTO, TizuloMorchida. Jogos Tradicionais infantis: o jogo a criança e a educação/Tizuco M. Kishimoto (org.); 2 ${ }^{\mathrm{a}}$. ed. Vozes. Petrópolis, 1993.

LOPES, Karina Rizek, Roseana Pereira Mendes, Vitória, Líbia Barreto de Faria, organizadoras. - Brasília: MEC. Secretaria de Educação Básica. Secretaria de Educação a Distância, 2006. 94p. (Livro de estudo: Módulo III, Coleção PROINFANTIL; Unidade 1).

LÜDKE. Menga. ANDRÉ, Marli E. D. A. Pesquisa em educação: abordagens qualitativas. São Paulo: EPU, 2012.

MATOS Marcela Moura, O Lúdico na Formação do Educador: Contribuições na Educação Infantil. Cairu em Revista. Jan 2013. Disponível em https://www.Cairu.br.artigo.2013-1, Acessado em 16/03/2019.

MINAYO, Maria Cecília de Souza (org.). Pesquisa Social: Teoria, método e criatividade. 18 ed. Petrópolis: Vozes, 1994.

PACHECO, Luci Mary Duso. PIOVESAN, Juliane. Educação do campo: desafios e perspectivas para a formação docente rural. In. Revista de Ciências Humanas. FW. v. 15, n. 24. p. 47-59.Jul. 2014. Disponível em: http://www.revistas.fw.uri.br/ index.php/revistadech/article/viewFile/1378/1726.

RICOEUR, Paul. O si-mesmo como um outro. Trad. Luci Moreira Cesar. Campinas: Papirus, 1991a.

RICOEUR. Paul. O Justo ou a essência da justiça. Trad. Vasco Cassimiro. Liboa: Instituto Piaget, $1995 \mathrm{~b}$.

RICOEUR, Paul. Amor e Justiça. Trad. Eduardo Brandão. São Paulo: WMF Fontes, 2012.

SANTOS, Magnólia Pereira dos. A Pedagogia Histórico-Crítica e a formação continuada de professores para as classes multisseriadas em escolas do campo. Amargosa-BA, 2016. Dissertação de Mestrado.

SILVA, A. P. S.; PASUCH, J. Orientações Curriculares Nacionais para a Educação Infantil do Campo. In: I Seminário Nacional: Currículo em Movimento Perspectivas Atuais, 2010, Belo Horizonte. I Seminário Nacional Currículo em Movimento - Perspectivas Atuais, 2010.

VYGOTSKY, L. S. A Formação Social da Mente: O Desenvolvimento dos Processos Psicológicos Superiores. São Paulo: Martins Fontes, 1994. 